"This document is the Accepted Manuscript version of a Published Work that appeared in final form in ACS Catalysis, copyright (C) 2019 American Chemical Society after peer review and technical editing by the publisher. To access the final edited and published work see [insert ACS Articles on Request author-directed link to Published Work, see: https://pubs.acs.org/doi/pdf/10.1021/acscatal.8b03953

\title{
Can Ni complexes behave as molecular water
}

\section{oxidation catalysts?}

Pablo Garrido-Barros ${ }^{\dagger+}$, Sergi Grau ${ }^{\dagger}$, Samuel Drouet ${ }^{\dagger,}$, Jordi Benet-Buchholz ${ }^{\dagger}$,Carolina GimbertSuriñach ${ }^{\dagger}$ and Antoni Llobet ${ }^{\dagger},, *$

†Institute of Chemical Research of Catalonia (ICIQ), Barcelona Institute of Science and Technology (BIST), Avgda. Països Catalans, 16,43007 Tarragona, Spain

\#Departament de Química Física i Inorgànica, Universitat Rovira i Virgili, Campus Sescelades, C/Marcel·lí Domingo, s/n, 43007 Tarragona, Spain

${ }^{\S}$ Departament de Química, Universitat Autònoma de Barcelona, 08193 Bellaterra, Spain 


\section{ABSTRACT}

The present report uncovers the borderline between homogeneous and heterogeneous water oxidation catalysis using a family of Ni complexes containing oxamidate anionic type of ligands. In particular, the $\mathrm{Ni}$ complex $\left[\left(\mathrm{L}^{1}\right) \mathrm{Ni}^{\mathrm{II}}\right]^{2-}\left(\mathbf{1}^{2-} ; \mathrm{L}^{1}=\right.$ o-phenylenebis(oxamidate)) and its modified analogues $\left[\left(\mathrm{L}^{2}\right) \mathrm{Ni}^{\mathrm{II}}\right]^{2-}\left(\mathbf{2}^{\mathbf{2 -}} ; \mathrm{L}^{2}=4,5\right.$-dimethyl-1,2-phenylenebis(oxamidate) $)$ and $\left[\left(\mathrm{L}^{3}\right) \mathrm{Ni}^{\mathrm{II}}\right]^{2-}\left(\mathbf{3}^{2-} ; \mathrm{L}^{2}=4-\right.$ methoxy-1,2-phenylenebis(oxamidate)) have been prepared and evaluated as molecular water oxidation catalysts at basic $\mathrm{pH}$. Their redox features have been analyzed by mean of electrochemical measurements revealing a crucial involvement of the ligand in the electron transfer processes. Moreover, the stability of those complexes has been assessed both in solution and immobilized on graphene-based electrodes at different potentials and $\mathrm{pHs}$. The degradation of the molecular species generates a NiOx layer, whose stability and activity as water oxidation catalyst has also been stablished. Electrochemical methods, together with surface characterization techniques, have shown the complex mechanistic scenario in water oxidation catalyzed by this family of $\mathrm{Ni}$ complexes, which consists of the coexistence of two catalytic mechanism: a homogeneous pathway driven by the molecular complex and a heterogeneous pathway based on NiOx. The electronic perturbations exerted through the ligand framework has manifested a strong influence over the stability of the molecular species under turnover conditions. Finally, $\mathbf{1}^{\mathbf{2}-}$ has been used as a molecular precursor for the formation of $\mathrm{NiFeOx}$ anodes that behave as extremely powerful water oxidation anodes.

KEYWORDS: Inorganic reaction mechanisms, water oxidation, water splitting, first row transition metal complexes, nickel catalyst, nickel oxide 


\section{Introduction}

Water oxidation to molecular dioxygen is not only an essential reaction in biology, due to its implications in the natural photosynthesis, ${ }^{1}$ but also a key step in the development of new sustainable energy schemes based on artificial photosynthesis..$^{2-4}$ In this context, molecular complexes based on first row transition metals (FR-TM) are attracting increasing attention as inexpensive homogeneous water oxidation catalysts (WOCs) that can potentially operate close to the thermodynamic limit. ${ }^{5-7}$

One of the attracting features of molecular WOCs is the existence of a synthetic versatility that thanks to the ligand variation allows to prepare a large variety of complexes where electronic, steric and supramolecular effects can be finely tuned. In addition there is a wide range of spectroscopic techniques that allows a deep characterization of molecular species including reactive intermediates. Thus molecular science is an ideal platform to study the reaction mechanism that operate in the water oxidation reaction as well as the factors that determine their activity and robustness. ${ }^{8}$

On the other hand, water oxidation requires a thermodynamic potential of $1.23 \mathrm{~V}$ vs NHE at $\mathrm{pH} 0$, plus an additional overpotential to overcome the kinetic barriers. This high potential value can promote total or partial ligand oxidation as a parallel undesired deactivation reactions. ${ }^{9-12}$ Besides, the relatively high metal-ligand bond lability of FR-TM complexes can lead to partial or total ligand substitution reactions by solvent molecules. The latter is favored at extreme $\mathrm{pH}$ values. ${ }^{13-17}$ This can foster the subsequent formation of metal oxides that can be responsible for the observed water oxidation catalysis. Therefore, deeper understanding of all these processes is essential to establish the real catalytic species that operate in a particular system and thus to obtain meaningful information for the design of more stable and active molecular catalyst.

Stability considerations are of special importance in Ni based molecular complexes due to its high affinity to form Ni oxide in aqueous solution upon oxidation. ${ }^{18-21}$ True homogeneous catalysis based on $\mathrm{Ni}$ complexes are rare and thus is a relatively unexplored field. ${ }^{22-24}$ 


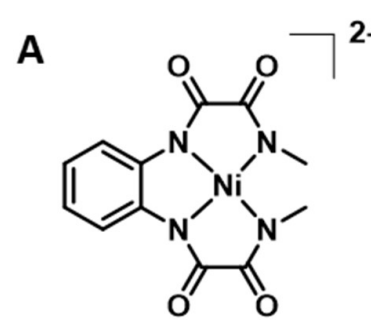

$\left[\left(\mathrm{L}^{1}\right) \mathrm{Ni}\right]^{2-}\left(1^{2-}\right)$<smiles>[Z2]CC(C)C</smiles>

$\left[\left(\mathrm{L}^{2}\right) \mathrm{Ni}\right]^{2-}\left(2^{2-}\right)$

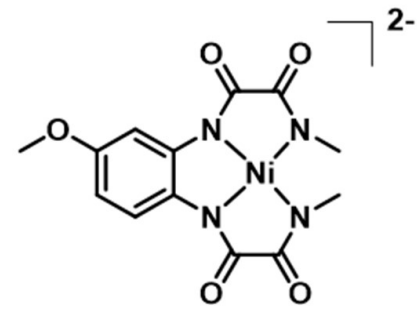

$\left[\left(\mathrm{L}^{3}\right) \mathrm{Ni}\right]^{2-}\left(3^{2-}\right)$

B
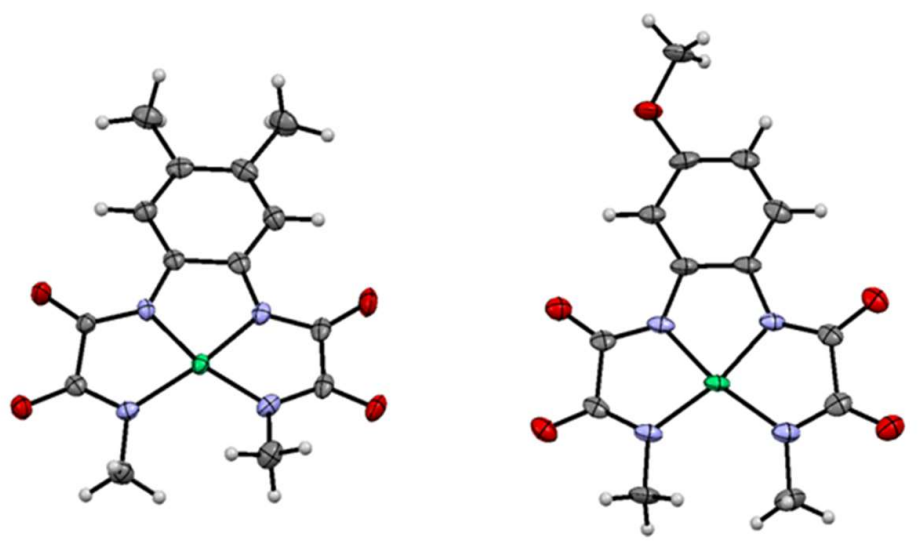

$2^{2-}$

C

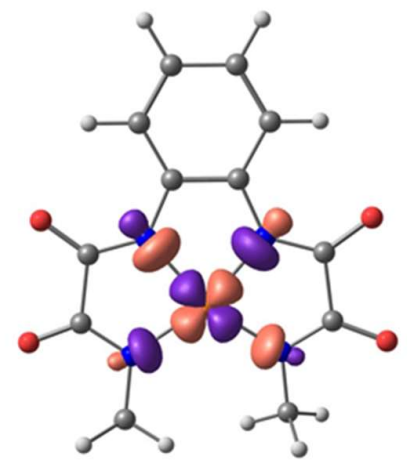

$\left[\left(\mathrm{L}^{1}\right) \mathrm{Cu}\right]^{2-}\left(4^{2-}\right)$

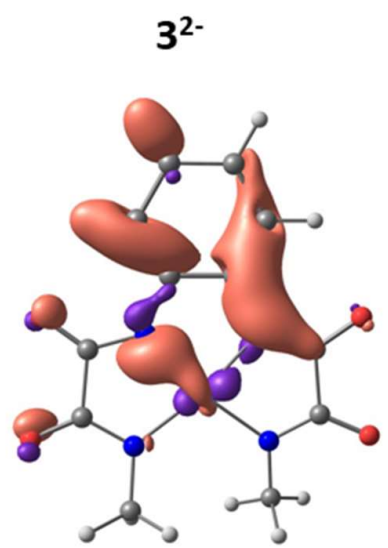

$\left[\left(\mathrm{L}^{1}\right) \mathrm{Ni}\right]^{2-}\left(1^{2-}\right)$

Figure 1. (A) Schematic representation and labeling of the homogeneous catalysts used in this work.

(B) ORTEP figure of complexes $\mathbf{2}^{\mathbf{2 -}}$ and $\mathbf{3}^{2-}$. (C) HOMO orbital of the copper and nickel complexes bearing ligand $\mathrm{L}^{1}$ calculated by Natural Orbital (NO) analysis.

In order to decipher the narrow line between homogeneous and heterogeneous catalysis using molecular Ni complexes, we have chosen the recently reported $\left[\left(\mathrm{L}^{1}\right) \mathrm{Ni}^{\mathrm{II}}\right]^{2-}\left(\mathrm{L}^{1}=\mathrm{o}-\right.$

phenylenebis(oxamidate)) complex, $\mathbf{1}^{\mathbf{2}-},{ }^{19}$ and its aryl substituted analogues $\left[\left(\mathrm{L}^{2}\right) \mathrm{Ni}^{\mathrm{II}}\right]^{2-}\left(\mathrm{L}^{2}=4,5-\right.$ 
dimethyl-1,2-phenylenebis(oxamidate), $\mathbf{2}^{\mathbf{2 -}}$, and $\left[\left(\mathrm{L}^{3}\right) \mathrm{Ni}^{\mathrm{II}}\right]^{2-}\left(\mathrm{L}^{2}=4-\right.$ methoxy-1,2-

phenylenebis(oxamidate)), $\mathbf{3}^{\mathbf{2}-}$ reported here for the first time (See Figure 1 for a drawn structure

and crystal structure). We study in depth the catalytic pathways available to this family of

complexes together with the deactivation paths that can lead to the formation of $\mathrm{NiOx}$.

\section{Results and discussion}

\section{Synthesis, structure and redox properties of $\mathbf{1}^{2-}-3^{2-}$}

We have prepared and characterized complexes $\mathbf{1}^{\mathbf{2}}, \mathbf{2}^{\mathbf{2 -}}$ and $\mathbf{3}^{\mathbf{2}-}$ in Figure $1 \mathrm{~A}$ following similar procedures described in the literature (See SI). ${ }^{23,25}$ As already reported for $\mathbf{1}^{\mathbf{2}}$, complexes $\mathbf{2}^{\mathbf{2 -}}$ and $\mathbf{3}^{\mathbf{2 -}}$ with $\mathrm{Me}$ and $\mathrm{MeO}$ substitution at the aromatic ring respectively, also feature a pseudo square-planar geometry typical of a low spin $\mathrm{d}^{8} \mathrm{Ni}(\mathrm{II})$ complex as shown in their crystal structure presented in Figure 1B. The Ni-N distances range from 1.852 to $1.918 \AA$ and are slightly shorter than those of the analogous copper complexes ${ }^{25}$ reflecting the strength and stability of the Nickel-amidate bonds.

A

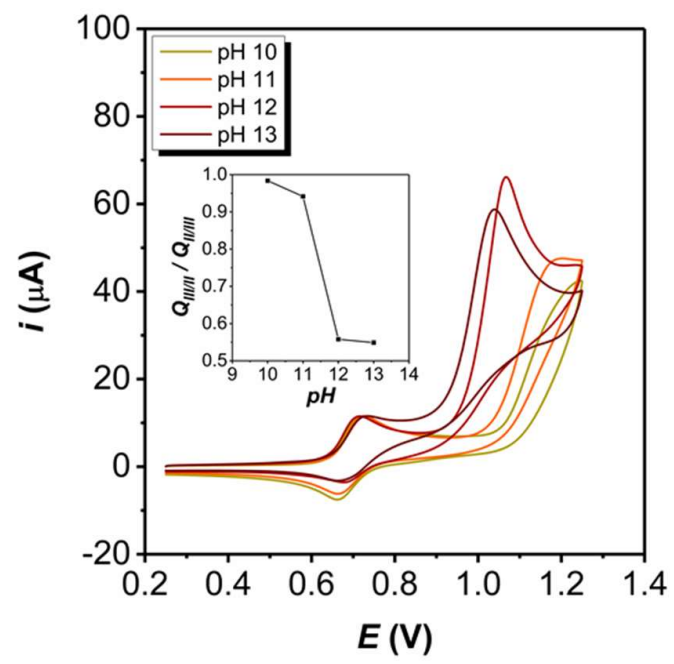

B

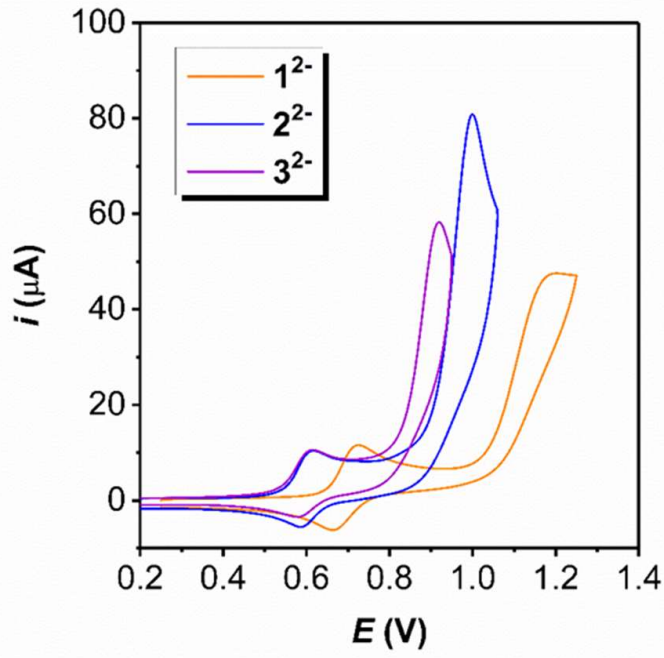

Figure 2. (A) CVs of $1 \mathrm{mM} \mathrm{1}^{2-}$ in aqueous solutions at different $\mathrm{pH}$ values. The inset figure shows the ratio between the reductive and oxidative charge ( $\mathrm{Q}_{\text {III/II }}$ and $\mathrm{Q}_{\mathrm{II} / \mathrm{III}}$ respectively) under the $\mathrm{Ni}{ }^{\mathrm{II}} / \mathrm{Ni}^{\mathrm{III}}$ redox wave as function of the $\mathrm{pH}$. (B) $\mathrm{CVs}$ of a solution containing $1 \mathrm{mM}$ of $\mathbf{1}^{\mathbf{2 -}}, \mathbf{2}^{\mathbf{2}-}$ and $\mathbf{3}^{\mathbf{2}}$ at $\mathrm{pH} 11$. 
Figure 2A shows the electrochemical behavior of $\mathbf{1}^{\mathbf{2}-}$ in basic aqueous solutions from $\mathrm{pH} 10$ to 13 . In this $\mathrm{pH}$ range, this complex is stable in solution over time as demonstrated by the lack of changes in its electrochemical performance (Figure S4), but it undergoes demetallation due to the protonation of the amidate groups at pHs lower than 10 . The cyclic voltammetry (CV) and differential pulse voltammetry (DPV) (Figure 2A and S3) reveal a first electrochemically quasi-reversible, chemically reversible metal based wave at $0.67 \mathrm{~V}$ due to the $\mathrm{pH}$-independent $\mathrm{Ni}(\mathrm{III}) / \mathrm{Ni}(\mathrm{II})$ redox couple, to form $\left[\left(\mathrm{L}^{1}\right) \mathrm{Ni}^{\mathrm{III}}\right]^{-}$. A UV-vis spectrum of the oxidized complex (Figure S5) confirms the metal based assignment and generation of the $\mathrm{Ni}(\mathrm{III})$ species at this $\mathrm{pH}$ based on the similarity with that obtained for the same complex in dry acetonitrile reported in the literature. ${ }^{26}$

At $\mathrm{pH} 10-13$ a second oxidation process due to the electrocatalytic oxidation of $\mathrm{H}_{2} \mathrm{O}$ to $\mathrm{O}_{2}$ is observed. The second oxidation takes place mainly at the aromatic ring generating a phenyl radical cation with concomitant coordination of a hydroxo group to form $\left[\left(\mathrm{L}^{1}\right) \mathrm{Ni}^{\mathrm{III}}(\mathrm{OH})\right]^{-}$(see Scheme 1, bottom). The latter species is responsible for the $\mathrm{O}-\mathrm{O}$ bond formation and final oxygen release as shown in Scheme 1. A Foot-of-the-wave analysis (FOWA) of the catalytic current ${ }^{27}$ allows us to calculate the observed kinetic constant for water oxidation resulting in a value around $0.20 \mathrm{~s}^{-1}$ (Figure S7). This is slightly lower than the $3.56 \mathrm{~s}^{-1}$ obtained for the analogous copper complex, manifesting the lower reactivity of the $\mathrm{Ni}$ catalyst that could be partly associated to the lower driving force due to the decrease in overpotential of the latter $(500 \mathrm{mV}$ for $\mathrm{Ni}$ vs $700 \mathrm{mV}$ for $\mathrm{Cu}$ at $\mathrm{pH}=12)$. 
Scheme 1. Catalytic cycle for water oxidation by complex $\mathbf{1}^{\mathbf{2}-}$ and mechanism for deactivation of complex $\mathbf{1}^{\mathbf{2}-}$ and formation of $\mathrm{NiOx}$.

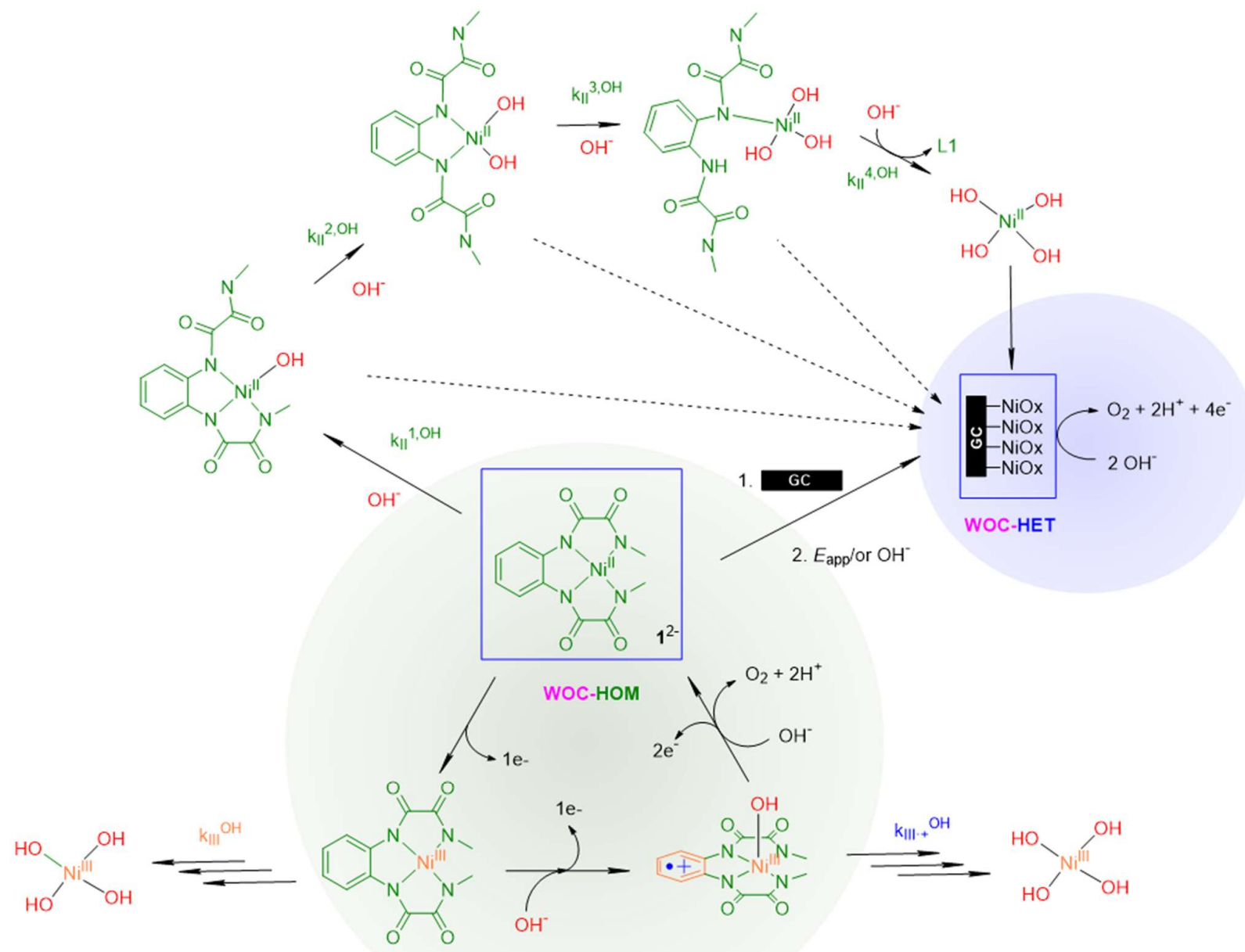

Similarly to $\mathbf{1}^{\mathbf{2}-}$, complexes $\mathbf{2}^{\mathbf{2 -}}$ and $\mathbf{3}^{\mathbf{2}-}$ feature two oxidation processes as shown in Figure $2 \mathrm{~B}$. In both cases, the electronic perturbations induced by the electron-donor substituents in the phenyl ring lead to a decrease in the overpotential for water oxidation of around 170 and $220 \mathrm{mV}$ respectively, supporting the assignment of a second ligand-based oxidation. In contrast to the analogous copper complexes, these modifications have also an influence on the first reversible wave that are cathodically shifted by approximately $100 \mathrm{mV}$. Since the metal coordination environment is practically identical in the 3 complexes, the change in the III/II potential can be attributed to a 
significant ligand contribution at their HOMO orbitals as shown by DFT calculations as opposed to the copper analogue $\left[\left(\mathrm{L}^{1}\right) \mathrm{Cu}\right]^{2-}, 4^{2-}($ Figure $1 \mathrm{C}$ and $\mathrm{S} 30) .{ }^{28}$

One of the most interesting features of catalyst $\mathbf{1}^{2-}$ arises from the reversibility observed in the first redox wave after going through the catalytic process, which is very unusual in Ni-based complexes proposed as water oxidation catalysts. ${ }^{22,24,29-32}$ Reversibility of precatalytic waves is an important indicator of robustness since it implies that the coordination environment in the metal center remains intact after catalytic turnovers. Regarding the substituted analogous, complex $\mathbf{2}^{\mathbf{2}-}$ also features similar reversible behavior while $\mathbf{3}^{2-}$ experiences a significant decrease in the reduction wave during the cathodic scan after the catalytic process. Similar results were obtained in the related family of copper complexes and point out to the presence of competing deactivation reaction possibly involving the reactive phenyl radical cation. ${ }^{25}$

\section{Molecular catalyst stability in homogeneous phase}

\subsection{Stability of the one electron oxidized derivative $\left[\left(\mathrm{L}^{1}\right) \mathrm{Ni}^{\mathrm{III}}\right]^{-}, \mathbf{1}^{-}$}

The stability of the oxidized species generated from the Ni(II) complex $\mathbf{1}^{2-}$, was monitored electrochemically at the $\mathrm{pH}$ range $10-13$. From $\mathrm{pH} 10$ to 12 , the $\mathrm{Ni}(\mathrm{III}) / \mathrm{Ni}(\mathrm{II})$ redox wave for $\mathbf{1}^{2-}$, shows a reversible behavior at $25-200 \mathrm{mV} \cdot \mathrm{s}^{-1}$ scan rates within the $0.25-0.85 \mathrm{~V}$ range where the corresponding $\mathrm{Ni}$ (III) complex is generated. Further, the intensity of the oxidative peak depends linearly with the square root of the scan rate, as expected for a diffusion controlled process from the Randles-Sevcik equation. However, at pH 13 the reversibility decreases with the scan rate and the oxidative current shows an important deviation of the Randles-Sevcik equation (see Figures S8-S9).

This result reveals that while the $\mathrm{Ni}(\mathrm{III})$ species $\mathbf{1}^{-}$, is fully stable within the $\mathrm{pH} 10-12$ within the $\mathrm{CV}$ timescales, at $\mathrm{pH}=13$, it likely undergoes progressive hydroxo substitution as proposed in equations 1-4 and graphically depicted in Scheme 1.

$$
\left[\mathrm{Ni}^{\mathrm{III}}\left(\mathrm{L}^{1}-\mathrm{k}-\mathrm{N}^{4}\right)\right]^{-}+\mathrm{OH}^{-}<->\left[\mathrm{Ni}^{\mathrm{III}}\left(\mathrm{L}^{1}-\mathrm{k}-\mathrm{N}^{3}\right)(\mathrm{OH})\right]^{2-}
$$




$$
\begin{aligned}
& {\left[\mathrm{Ni}^{\mathrm{III}}\left(\mathrm{L}^{1}-\mathrm{k}-\mathrm{N}^{3}\right)(\mathrm{OH})\right]^{2-}+\mathrm{OH}^{-}<->\left[\mathrm{Ni}^{\mathrm{III}}\left(\mathrm{L}^{1}-\mathrm{K}^{-N^{2}}\right)(\mathrm{OH})_{2}\right]^{3-}} \\
& {\left[\mathrm{Ni}^{\mathrm{III}}\left(\mathrm{L}^{1}-\mathrm{k}-\mathrm{N}^{2}\right)(\mathrm{OH})_{2}\right]^{3-}+\mathrm{OH}^{-}<->\left[\mathrm{Ni}^{\mathrm{III}}\left(\mathrm{L}^{1}-\mathrm{k}-\mathrm{N}^{1}\right)(\mathrm{OH})_{3}\right]^{4-}} \\
& {\left[\mathrm{Ni}^{\mathrm{III}}\left(\mathrm{L}^{1}-\mathrm{k}-\mathrm{N}^{1}\right)(\mathrm{OH})_{3}\right]^{4-}+\mathrm{OH}^{-}<->\left[\mathrm{Ni}^{\mathrm{III}}(\mathrm{OH})_{4}\right]^{-}+\mathrm{L}^{14-}}
\end{aligned}
$$

\subsection{Formation of ligand radical cation $\left[\left(\mathrm{L}^{1}\right)^{-} \mathrm{Ni}^{\mathrm{III}}(\mathrm{OH})\right]^{-}$and catalysis at different $\mathrm{pHs}$}

The stability of complex $\mathbf{1}^{2-}$ was also evaluated during electrocatalytic process at $\mathrm{pH}$ 10-13 by monitoring the ratio between the charge under the reductive and oxidative waves $\left(\mathrm{Q}_{\mathrm{III} / \mathrm{II}} / \mathrm{Q}_{\mathrm{II} / \mathrm{III}}\right)$ calculated by integration of the $\mathrm{Ni}^{\mathrm{II}} / \mathrm{Ni}^{\mathrm{III}}$ redox wave of the $\mathrm{CVs}$ (See inset in Figure 2). This ratio is very close to 1 when working at $\mathrm{pH} 10$ but drastically drops at higher $\mathrm{pH}$, suggesting an important decrease in the stability of the complex during catalysis turnover at higher $\mathrm{pH}$.

Here besides the potential substitution processes described in equations 1-4 that can also occur in this doubly oxidized species, there is an additional pathway for degradation that involves the phenyl radical cation species present in $\left[\left(\mathrm{L}^{1}\right)^{\prime} \mathrm{Ni}^{\mathrm{III}}(\mathrm{OH})\right]^{-}, \mathbf{1}(\mathbf{O H})^{-}$. Indeed, this species will be highly reactive towards the hydroxylation of the aromatic ring with the $\mathrm{OH}^{-}$present in the medium that in turn is competing with the O-O bond formation that drives the desired catalytic process (Scheme 1, bottom right). The relative ratios of these two reactions will dictate the stability of the initial complex and thus its ruggedness as a water oxidation catalyst. 
A

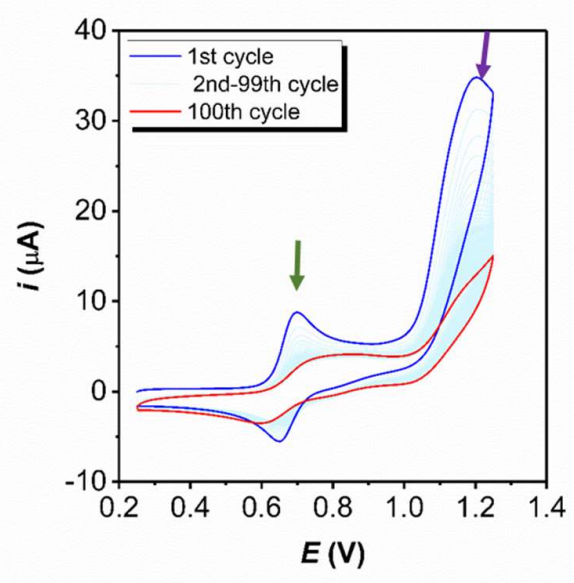

C

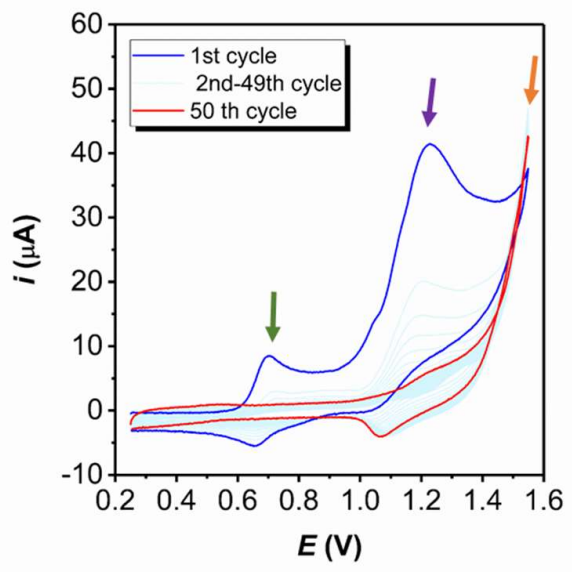

B

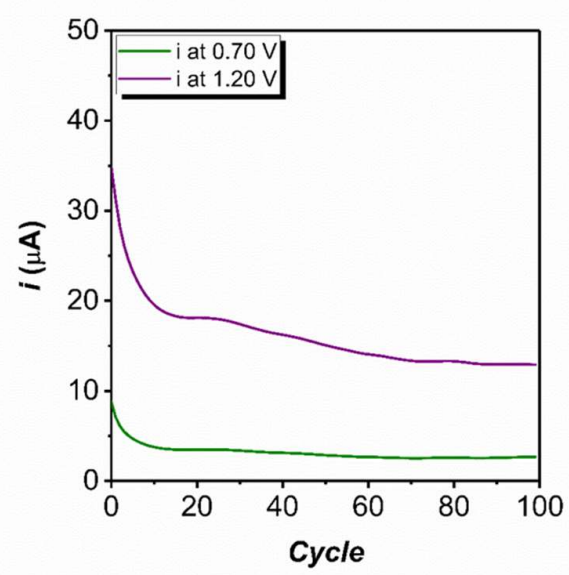

D

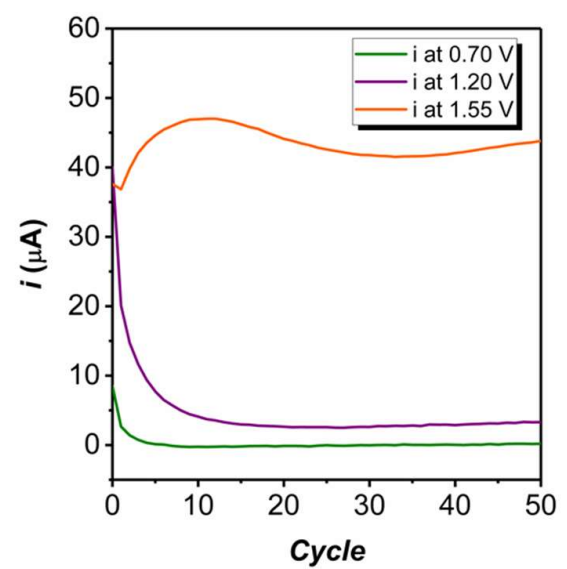

Figure 3. (A) 100 consecutive CVs in an aqueous solution containing $1 \mathrm{mM}$ of $\mathbf{1}^{\mathbf{2}}$ at $\mathrm{pH} 10$ from 0.25 V to $1.25 \mathrm{~V}$. (B) Evolution of the intensity at $0.70 \mathrm{~V}$ and $1.20 \mathrm{~V}$ with the consecutive cycles. (C) 100 consecutive $\mathrm{CVs}$ in an aqueous solution containing $1 \mathrm{mM}$ of $\mathbf{1}^{2-}$ at $\mathrm{pH} 10$ from $0.25 \mathrm{~V}$ to $1.55 \mathrm{~V}$. (D) Evolution of the intensity at $0.70 \mathrm{~V}, 1.20 \mathrm{~V}$ and $1.55 \mathrm{~V}$ with the consecutive cycles.

The stability of $\mathbf{1}^{2-}$ as catalyst at longer time scales was monitored via repetitive CVs at a scan rate of $100 \mathrm{mV} / \mathrm{s}$ in the potential range from 0.25 to $1.25 \mathrm{~V}$ for 100 consecutive scans in the $\mathrm{pH}$ range 10 14. Figure $3 \mathrm{~A}$ shows that at $\mathrm{pH}=10$ for the first cycle the degree of degradation is practically nonexistent as judged by the reversibility of the III/II couple. However, upon repetitive cycles, Figure 3B shows that the intensity of the anodic peak decreases by half after 10 cycles as is also the case of the catalytic current (see green and purple lines, respectively). This decrease continues in the following cycles suggesting the presence of a deactivation pathway that generates inactive species. Figure $3 \mathrm{C}$ 
illustrates the effect of increasing the anodic potential up to $1.50 \mathrm{~V}$. In this potential range, even after the first cycle the returning cathodic wave of the III/II couple reduces its intensity by half with regards to its anodic counterpart. Further cycling shows the typical waves associated with the formation of $\mathrm{NiOx} / \mathrm{NiOOHx}$ that remain attached at the surface of the electrode: the $\mathrm{Ni}(\mathrm{II}) / \mathrm{Ni}(\mathrm{III})$ at $E_{\mathrm{a}} \approx 1.2 \mathrm{~V}$ and the catalytic wave starting at $E_{\mathrm{cat}} \approx 1.45 \mathrm{~V}$.

Thus under these conditions it seems that the homogeneous catalysts is competing with two other reactions: one that deactivates the catalyst towards the formation of aromatic hydroxylated species that have no water oxidation activity and a second one that triggers the formation of $\mathrm{NiOx} / \mathrm{NiOOHx}$ that absorb at the surface of the electrode and that is the active catalyst towards the water oxidation reaction at higher potential than the molecular catalyst. 
A

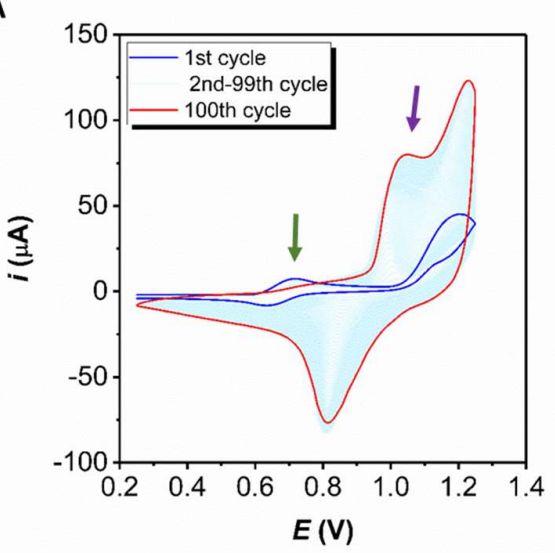

C

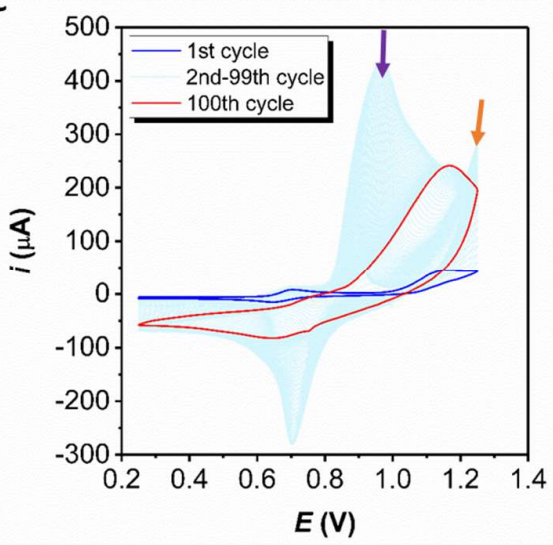

$\mathbf{E}$

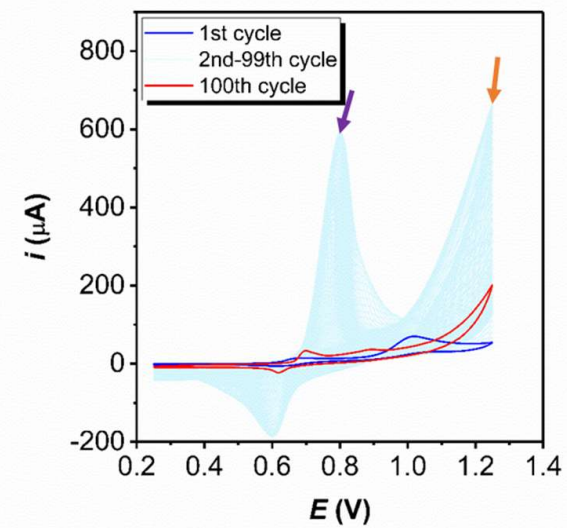

B

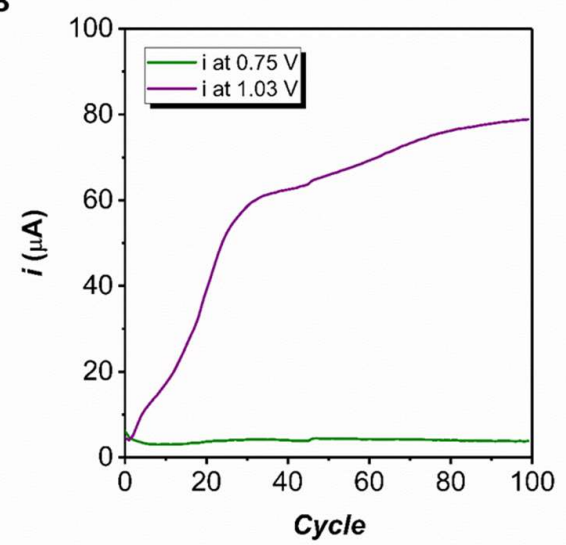

D

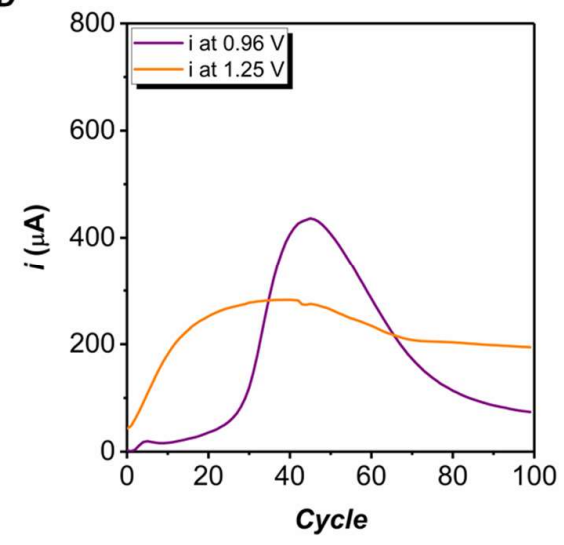

$\mathbf{F}$

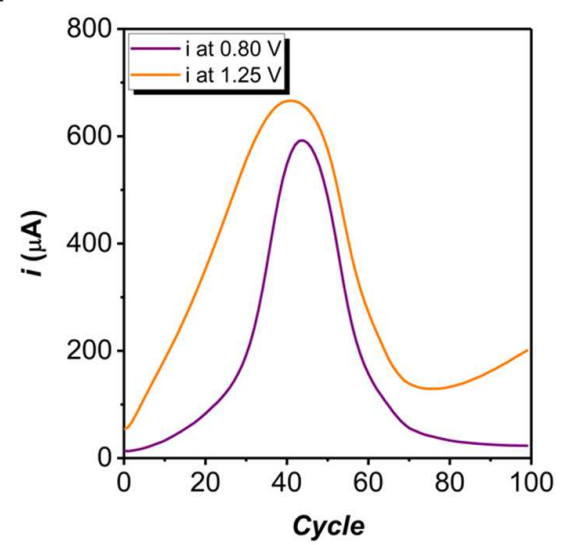

Figure 4. (A) 100 consecutive $\mathrm{CVs}$ in an aqueous solution containing $1 \mathrm{mM}$ of $\mathbf{1}^{\mathbf{2}-}$ at $\mathrm{pH} 11$. (B) Evolution of the intensity at $0.75 \mathrm{~V}$ and $1.03 \mathrm{~V}$ with the consecutive cycles. (C) 100 consecutive CVs in an aqueous solution containing $1 \mathrm{mM}$ of $\mathbf{1}^{2-}$ at $\mathrm{pH}$ 12. (D) Evolution of the intensity at $0.96 \mathrm{~V}$ and $1.25 \mathrm{~V}$ with the consecutive cycles. (E) 100 consecutive CVs in an aqueous solution containing $1 \mathrm{mM}$ of $\mathbf{1}^{2-}$ at $\mathrm{pH}$ 13. (B) Evolution of the intensity at $0.80 \mathrm{~V}$ and $1.25 \mathrm{~V}$ with the consecutive cycles. 
At $\mathrm{pH}=11$ the repetitive CVs displayed in Figure 4A and analyzed in Figure 4B, show that the wave associated with $\mathrm{NiOx} / \mathrm{NiOOHx}$ (intensity at $1.03 \mathrm{~V}$ represented as the purple line) increases as the III/II wave of the complex (intensity at $0.75 \mathrm{~V}$, green line) decreases suggesting that the dominant pathway here is the formation of the $\mathrm{NiOx} / \mathrm{NiOOHx}$. Interestingly the amount of deposited oxide increases mainly linearly up to 25 cycles and then slightly levels off suggesting a saturation at the surface of the electrode. The catalytic activity of this $\mathrm{NiOx} / \mathrm{NiOOHx}$ lies at higher potentials that are not represented in the CV scale.

At $\mathrm{pH}=12$, the formation of the $\mathrm{NiOx} / \mathrm{NiOOHx}$ takes place readily reflecting the high impact of increasing the $\mathrm{pH}$ (Figure 4C). At the initial cycles the activity of the formed NiOx, represented by the intensity at $1.25 \mathrm{~V}$ (orange line), lies at similar potential as the catalytic wave of the molecular complex and grows linearly while the amount of deposited NiOx remain low as can be inferred from the current intensity at $0.96 \mathrm{~V}$ (purple line). After an induction period of around 20 cycles, the deposition of $\mathrm{NiOx}$ increases exponentially while the activity reaches a plateau. After 40 cycles the deposited NiOx starts to redissolve as reflected by the strong decay in the intensity whereas the activity keeps approximately constant. Finally, at pH 13, Figures 4E,F, a similar behavior is found except for the activity of the $\mathrm{NiOx}$ that after reaching 40 cycles, decreases together with the amount of deposited NiOx. These last results at $\mathrm{pH}>12$ indicate that, beside the $\mathrm{NiOx} / \mathrm{NiOOHx}$ formation, there is a second process that dissolves that material in the solution taking place at longer timescale.

\subsection{The impact of the applied potential $\left(E_{\mathrm{app}}\right)$}

The stability of $\mathbf{1}^{2-}$ was also analyzed as a function of the applied potential using potentiostatic methodologies. Controlled potential electrolysis (CPE) experiments were first conducted at a lower potential of $0.85 \mathrm{~V}$ (Figure S11) where just the one electron oxidized Ni(III) species $\mathbf{1}^{-}$is generated. At $\mathrm{pH}<12$ the molecular complex was stable against degradation and formation of $\mathrm{NiOx} / \mathrm{NiOOHx}$. On the other hand, $\mathrm{NiOx} / \mathrm{NiOOHx}$ was confirmed after $\mathrm{CPE}$ at $\mathrm{pH} 12-13$ by a continuous increase in the electrochemical activity of the used electrode when analyzed in a fresh buffer solution (Figure 
S11C, D). EDX and XPS confirmed the presence of NiOx species at higher pHs but only for the electrodes with high loading (Figure S26). This fact reflects the high sensitivity of the electrochemical techniques to detect even low amounts of deposited materials with characteristic redox features. When the same experiment of generating $\mathbf{1}^{-}$potentiostatically is performed in $\mathrm{pH} 12$ solutions and at lower potential $\left(E_{\text {app }}=0.7 \mathrm{~V}\right)$, formation of $\mathrm{NiOx}$ is avoided as depicted in Figure $5 \mathrm{~A}, \mathrm{~B}$. This is in sharp contrast to the results obtained with a similar experiment at $E_{\text {app }}=0.7 \mathrm{~V}$ in the presence of free metal ions, which showed a clear formation of NiOx on the electrode (Figure S12). All these results confirm that $\mathrm{NiOx}$ deposited from 1' 1 $^{-}$comes from $\mathrm{Ni}$ ions in solutions, which are generated by the substitution reactions in equations 1-4 under certain $E_{\text {app }}$ and $\mathrm{pH}$ conditions.
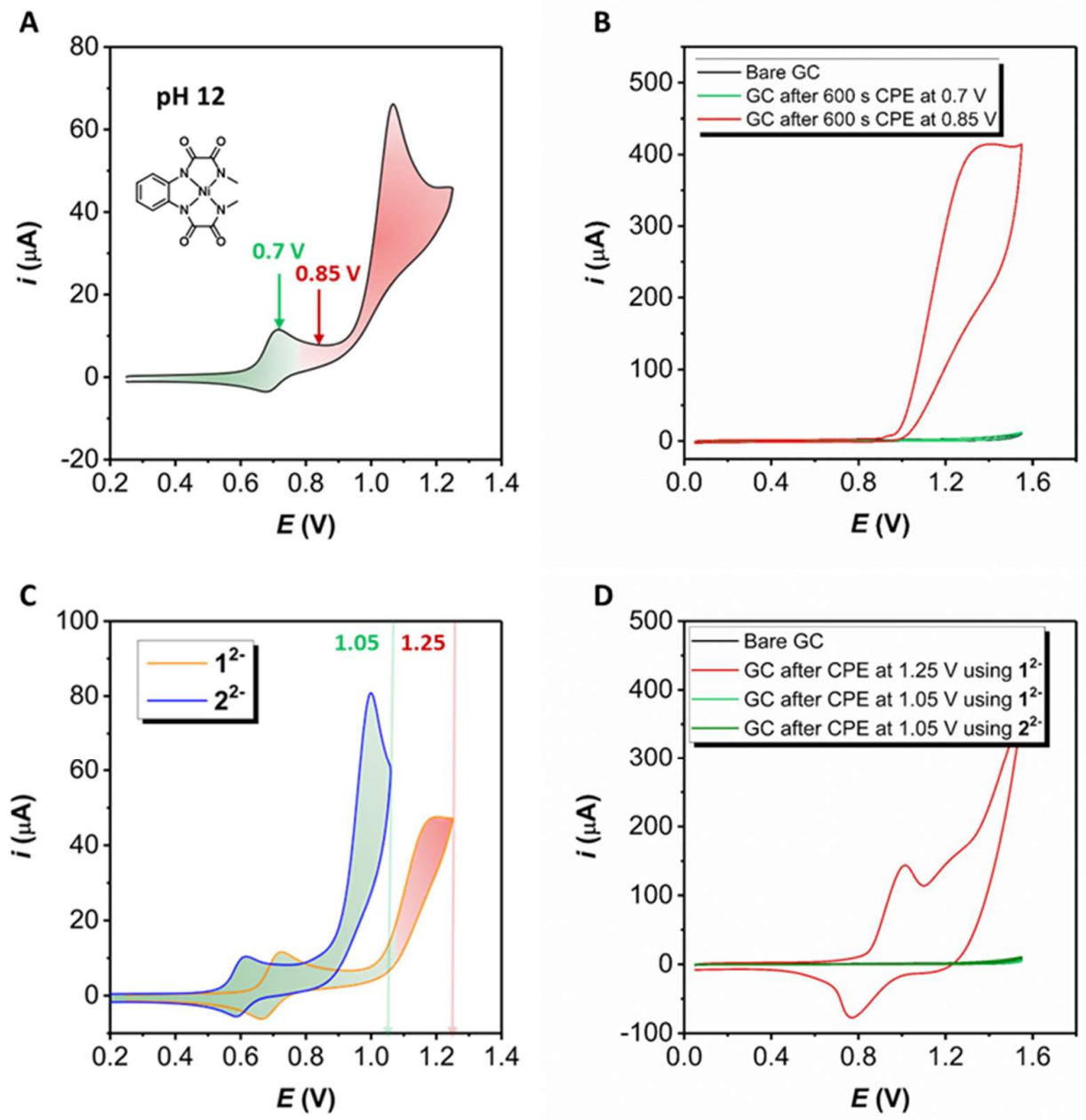

Figure 5. (A) CVs of $1 \mathrm{mM}$ solution of complex $\mathbf{1}^{2-}$ in aqueous phosphate buffer at $\mathrm{pH}$ 12. (B) CVs in a fresh buffer solution at $\mathrm{pH} 12$ of a bare GC electrode (black line) and GC electrodes after CPE 
in a $1 \mathrm{mM}$ solution of $\mathbf{1}^{\mathbf{2}-}$ at different potentials (red and green lines). (C) CVs of $1 \mathrm{mM}$ solution of complex $\mathbf{1}^{\mathbf{2}-}$ and $\mathbf{2}^{\mathbf{2 -}}$ in aqueous phosphate buffer at $\mathrm{pH}$ 11. (D) CVs in a fresh buffer solution at $\mathrm{pH}$ 11 of a bare GC electrode (black line) and GC electrodes after $3600 \mathrm{~s} \mathrm{CPE}$ at $1.25 \mathrm{~V}$ (red line) and $1.05 \mathrm{~V}$ (green line) in a $1 \mathrm{mM}$ solution of $\mathbf{1}^{\mathbf{2}-}$ and $\mathbf{2}^{\mathbf{2 -}}$ respectively. Green and red zones represent the conditions under which $\mathrm{NiOx}$ was present and absent respectively after CPE. GC disk was used as working electrode and the scan rate was set to $100 \mathrm{mV} / \mathrm{s}$.

CPE experiments were also conducted at higher potentials to assess the stability under catalysis. Figure 5C,D shows the response of the electrode in a clean electrolyte solution after applying higher potentials of 1.05 and $1.25 \mathrm{~V}$ for $1 \mathrm{~h}$ at $\mathrm{pH} 11$. At the $E_{\mathrm{app}}=1.05 \mathrm{~V}$ no NiOx can be observed and thus manifests the high stability of the $\mathrm{Ni}(\mathrm{III})$ species in $\mathbf{1}^{-}$(green line, Figure 5D) indicating that the substitution processes shown in equations 1-4 are negligible under these conditions. However, when the $E_{\text {app }}=1.25 \mathrm{~V}$, the formation of the $\mathrm{NiOx}$ is evident (red line, Figure 5D)and thus points out towards the degradation of the initial molecular complex as was described for the previous section using voltammetric techniques.

At $\mathrm{pH} 10$, similar behavior is observed with formation of $\mathrm{NiOx}$ only at the highest potential of 1.25 $\mathrm{V}$ (Figure S14 and S15). At pH values of 12 and 13, NiOx is also formed under catalytic conditions, although the speed of formation and the final $\mathrm{NiOx}$ amount is much higher than at lower $\mathrm{pH}$ values, which is in agreement with previous voltammetric measurements (Figure S14 and S15). Moreover, similar saturation process and final decay of the NiOx activity are present at $\mathrm{pH} 12$ and 13, since the catalytic activity of the $\mathrm{NiOx}$ increases during the first $120 \mathrm{~s}$ but then it significantly decreases until $600 \mathrm{~s}$.

\subsection{The unique case of stabilization by Me groups in $\mathbf{2}^{\mathbf{2}}$}

Similar experiments were carried out for $\mathbf{2}^{2-}$, where the benzene ring is substituted with two methyl groups with regard to $\mathbf{1}^{2-}$. As already mentioned, at an $E_{\text {app }}=1.05 \mathrm{~V}$ for $1 \mathrm{~h}$ at $\mathrm{pH} 11$, catalyst $\mathbf{1}^{\mathbf{2}-}$ does not degrade to form $\mathrm{NiOx}$, even though at this potential the catalytic currents is rather low. In contrast, 
catalyst $\mathbf{2}^{2-}$ shows high current intensity values in the same experimental conditions due to the cathodic shift of the waves induced by the electron-donating methyl groups. Thus, at $E_{\text {app }}=1.05 \mathrm{~V}$ the reaction takes place well beyond the electrocatalytic current for $\mathbf{2}^{2-}$ (Figure 5C). Interestingly, this complex shows a spectacular stability as demonstrated by the absence of any NiOx absorbed at the electrode (Figure 5D). These results reveal that neither equations 1-4 nor the deactivation process proposed for the cation radical $\left[\left(\mathrm{L}^{1}\right) \mathrm{Ni}^{\mathrm{III}}(\mathrm{OH})\right]^{-}$operate at any significant length. On the other hand, as in the previous case, increasing the $\mathrm{pH}$ increases the $\mathrm{OH}^{-}$concentration that in turn habilitate the deactivation pathways. Thus, similar experiments carried out for $\mathbf{2}^{2-}$ at $\mathrm{pH} 12$ and 13 generate $\mathrm{NiOx}$ at the surface of the electrode as can be seen in Figure S17.

The high stability of complex $\mathbf{2}^{2-}$ under catalytic conditions in $\mathrm{pH} 11$ shown in Figure $5 \mathrm{C}, \mathrm{D}$ is not only very remarkable but actually unprecedented in molecular Ni complexes. The extra stability of the $\mathbf{2}^{2-}$ as compared to $\mathbf{1}^{2-}$ is due to the electronic effects exerted by the two methyl groups at the aromatic moiety of the ligand over the stability of singly and doubly oxidized $\mathrm{Ni}(\mathrm{III})$ and $\mathrm{Ni}(\mathrm{III})-\mathrm{OH}-$ radical cation species. This electronic effect can be appreciated in the CV of Figure $5 \mathrm{C}$ for $\mathbf{2}^{2-}$ where the redox potentials decrease by approximately $200 \mathrm{mV}$ for each redox couple with respect to that of $\mathbf{1}^{2-}$

\section{Molecular catalyst stability in heterogeneous phase}

To test the stability of the molecular catalyst in heterogeneous phase, complex $\mathbf{1}^{2-}$ was anchored on Graphene sheets via pi-pi stacking interactions in a similar manner as it had previously been done for related $\mathrm{Cu}$ complexes with the same ligand. ${ }^{33}$ The procedure consists of suspending the Graphene sheets in a $1 \mathrm{mM}$ of the complex and stirring the mixture overnight. After separation and washing of the functionalized graphenic material, it was dropcasted on a glassy carbon (GC) electrode generating the $\mathbf{G} @ \mathbf{1}^{2-}$ hybrid materials (see experimental section in the SI for additional details). 
A

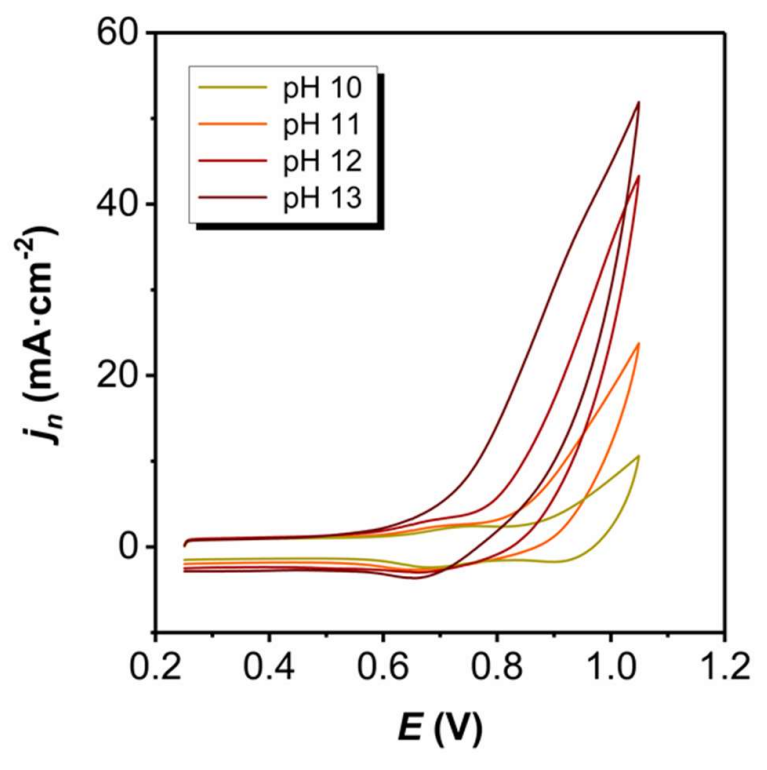

B

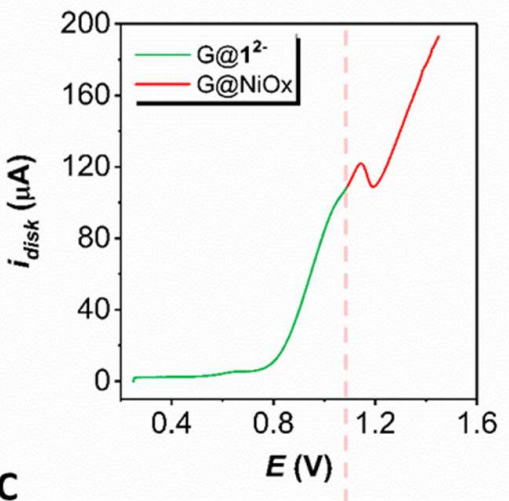

C

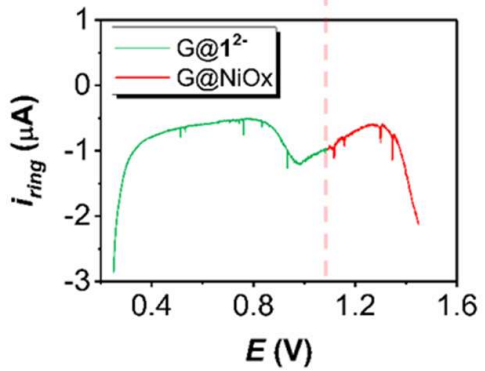

Figure 6. (A) CVs of G@12- electrodes in aqueous solutions at different pH values (B) LSV of G@12/NiOx generated after cycling a G@12- electrode for four times in the range from 0.3 to $1.05 \mathrm{~V}$. The hybrid material was supported on the disk of a RRDE in phosphate buffer at $\mathrm{pH} 11$. Experiment was performed under nitrogen atmosphere and at $1600 \mathrm{rpm}$. (C) Simultaneous CPE at $-0.35 \mathrm{~V}$ performed in the Pt ring of the RRDE for the reduction of the generated oxygen. Green color represents the molecular domain while red color refers to the electrochemical response of the NiOx.

The performance of $\mathbf{G} @ \mathbf{1}^{2-}$ was assessed by electrochemical techniques including CV, DPV and rotating ring disk electrode (RRDE). The CVs at $\mathrm{pH} 10-14$ are displayed in Figure 6A, which shows a relatively similar behavior as in homogeneous phase except that the onset of the catalytic waves are shifted by $100 \mathrm{mV}$ toward the cathodic region. This is a result of the pi-interaction of the graphene with the pi- system of complex $\mathbf{1}^{2-}$, in a similar manner as had been previously observed for the $\mathrm{Cu}$ analogue $\left[\left(\mathrm{L}^{1}\right) \mathrm{Cu}\right]^{2-}, \mathbf{4}^{2-33}$ 
Repetitive cyclic voltammetric experiments (Figure S18) similar to the ones performed in homogeneous phase display a relatively similar behavior and thus show that the anchoring process do not stabilize the molecular catalyst against the formation of $\mathrm{NiOx}$.

To further characterize these hybrid materials the graphene sheets functionalized with $\mathbf{1}^{\mathbf{2}-}$ were deposited at the surface of the graphitic working electrode of a RRDE and the results are displayed in Figure 6B,C and S19.

A linear sweep voltammetry (LSV) at $2 \mathrm{mV} / \mathrm{s}$ from 0.3 to $1.5 \mathrm{~V}$ for $\mathbf{G} @\left(\mathbf{1}^{2-} / \mathbf{N i O x}\right)$ is shown in Figure $6 \mathrm{~B}$ at $\mathrm{pH} 11.0$ after depositing a mixture of the molecular catalyst and $\mathrm{NiOx}$ at the surface of the working electrode, following the protocol described in the SI, while the ring disk potential was fixed at $-0.35 \mathrm{~V}$ where the reduction of oxygen to superoxide occurs (Figure 6C). ${ }^{33}$ The Figures show that the first release of oxygen is detected under the catalytic wave of the molecular species, at potential values between 0.65 and $0.80 \mathrm{~V}$. Further, there is a second increase in the oxygen detected due to the NiOx at higher potentials (with onset at ca. $1.3 \mathrm{~V}$ ). The two phenomena can be clearly distinguished since the rate at which oxygen is formed is different and this is translated into a change in curvature that is clearly appreciated in Figure 6B and C. Similar phenomena can be observed at other pHs as shown in Figure S19.

\section{Preparation and water oxidation performance of $\mathrm{NiFeOOH}$ from $1^{2-}$}

As already demonstrated, NiOx owes its high activity for water oxidation partly due to the incorporation of $\mathrm{Fe}$ impurities from the solution forming $\mathrm{Ni}_{1-\mathrm{x}} \mathrm{Fe}_{\mathrm{x}}(\mathrm{OH})_{2}$ films. ${ }^{34,35}$ It has been found that an iron composition between $5-25 \%$ provides the electrodes with the maximum activity at the lowest overpotential. Therefore, using the optimal conditions that we found for NiOx deposition from the homogeneous catalyst $\mathbf{1}^{2-}(\mathrm{CPE}$ at $0.85 \mathrm{~V}$ and $\mathrm{pH} 13)$ we prepared new $\mathrm{Ni}_{1-\mathrm{x}} \mathrm{Fe}_{\mathrm{x}}(\mathrm{OH})_{2}$ electrodes in the presence of $0.05 \mathrm{mM}$ of $\mathrm{Fe}^{\mathrm{II}}\left(\mathrm{ClO}_{4}\right)_{2}$, based on reported methodologies for cathodic codeposition (SI for details). ${ }^{36}$ As expected, this procedure led to electrodes with largely improved catalytic performance in comparison with the previous ones due to the greater incorporation of Fe atoms in the 
oxide structure (Figure 7). XPS and EDX analysis of the material deposited on GC plates electrodes confirm the presence of $\mathrm{Ni}_{1-\mathrm{x}} \mathrm{Fe}_{\mathrm{x}}(\mathrm{OH})_{2}$ species on the surface, with around 7-10\% of Fe (Figure $\mathrm{S} 27$ and S28). SEM images of the same electrodes revealed the formation of a film of material extended over the whole surface of the electrode (Figure S29).

Control of the total charge passed in the CPE during deposition resulted in different loadings of this material, as calculated by integration of the oxidative $\mathrm{Ni}{ }^{\mathrm{II}} / \mathrm{Ni}^{\mathrm{III}}$ wave (Figure $\mathrm{S} 21$ and $\mathrm{S} 22$ ). ${ }^{37}$ The calculated surface coverage ranged from 1 to a maximum of $50 \mathrm{nmol} \cdot \mathrm{cm}^{-2}$, which are in general low loading values compare to most of the reported $\mathrm{Ni}_{1-\mathrm{x}} \mathrm{Fe}_{\mathrm{x}}(\mathrm{OH})_{2}$ materials prepared with different methods. ${ }^{36}$ This fact can be explained as there is only a partial degradation of the molecular complex induced by the electrode within the time scale of the CPE (0-600s).

We also analyzed the Electrochemically Active Surface Area (ECSA) measuring the non-Faradaic capacitive current as a function of the scan rate $^{38}$ (Figure S23) resulting in an average value of 0.17 $\pm 0.06 \mathrm{~cm}^{2}$. The ECSA was calculated for the different electrodes but in all the cases the value ranged from 0.075 to $0.218 \mathrm{~cm}^{2}$ without apparent dependence on the loading. This suggests that the increase in the metal loading increases the number of internal layers, keeping the electroactive surface and thus the exposed catalytic sites approximately constant. These values for the ECSA are relatively low compared to other reported $\mathrm{NiFeOx}$, as expected from the low loading.

We further assessed the performance of these active electrodes following standard methodologies previously described to compare metal oxides. ${ }^{37,38}$ Firstly, using a RRDE we evaluated the Faradaic efficiency for water oxidation, resulting essentially in $100 \%$ as reported for many other oxides in alkaline conditions (Figure S24). As metrics to compare the catalytic activity of heterogeneous metal oxides, many parameters have been described, referred to the amount of deposited material. The most popular ones are the specific current density and the Turnover Frequency (TOF) at certain overpotential (normally $300-350 \mathrm{mV}$ ), as defined in the literature. ${ }^{37,38}$ These two standard parameters allow for fair comparison among the catalyst reported, so we have calculated them as a function of the loading of our active electrodes. As deducted from the results summarized in Figure S25, the 
current density at $\eta=300 \mathrm{mV}$ decreases as the loading of the electrode increases, featuring the maximum values between 1 and $6 \mathrm{nmol} \cdot \mathrm{cm}^{-2}$. Figure 7A shows the $\mathrm{CV}$ for an electrode featuring one of the maximum current densities of around 3.57 and $11.77 \mathrm{~mA} \cdot \mathrm{cm}^{-2}$ at 300 and $350 \mathrm{mV}$ respectively, or 1.42 and $4.86 \mathrm{~mA} \cdot \mathrm{cm}^{-2}$ considering the ECSA instead of geometric area. Those maximum values are among the highest reported for $\mathrm{NiFeOx}$ electrodes, despite the low loading and ECSA values of our electrodes. ${ }^{18,37-42}$ Similar observation were made when analyzing the TOF at $\eta=300$ and 350 using the integration of the $\mathrm{Ni}(\mathrm{II}) / \mathrm{Ni}(\mathrm{III})$ oxidation peak as measurement for the estimation of the total metal sites. There is a significant increase in the TOF as the deposited material decreases, reaching maximum values around 2 and $11 \mathrm{~s}^{-1}$ at overpotential values of 300 and $350 \mathrm{mV}$ respectively (Figure 7B). Those TOF values exceed other high performance $\mathrm{NiFeOx}$ catalysts as well as other metal oxides electrodes, although comparison should be made carefully according to the employed TOF calculation method. ${ }^{37}$

A

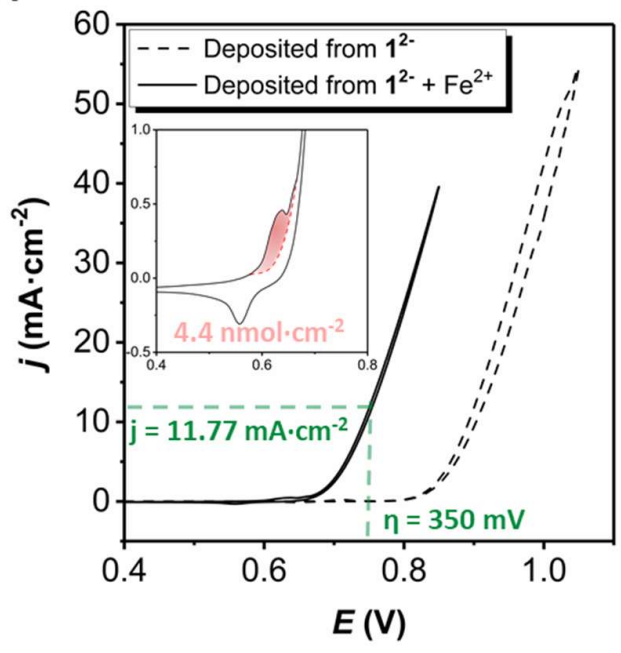

B

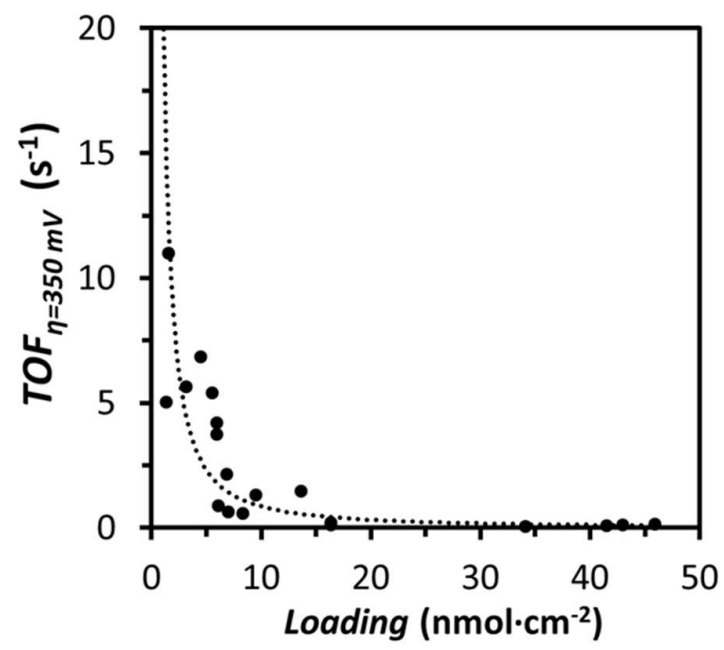

Figure 7. (A) $\mathrm{CV}$ of one $\mathrm{NiFeOx}$ on $\mathrm{GC}$ electrode in a $1 \mathrm{M} \mathrm{KOH}$ aqueous solutions at $10 \mathrm{mV} / \mathrm{s}$. Inset shows a zoom of the redox wave corresponding to the $\mathrm{Ni}{ }^{\mathrm{II}} / \mathrm{Ni}^{i \mathrm{II}}$ couple with a loading of $4.4 \mathrm{nmol} \cdot \mathrm{cm}^{-}$ ${ }^{2}$ calculated from integration of the red area. (B) Representation of the TOF values calculated at $\eta=350$ $\mathrm{mV}$ for electrodes with different loading values. 
These results demonstrate that there is a clear benefit when codepositing $\mathrm{Ni}_{1-\mathrm{x}} \mathrm{Fe}_{\mathrm{x}}(\mathrm{OH})_{2}$ from the molecular Ni complex $\mathbf{1}^{\mathbf{2}-}$ by degradation due to molecule-electrode interactions, compared to traditional methods.

\section{Conclusions}

The present work shows how slight modification of different experimental conditions namely, $\mathrm{pH}$, $E_{\text {app }}$, time of exposure (scan rate) can determine the robustness of molecular Ni complexes influencing both the amount and nature (electrocatalytic activity) of the derived $\mathrm{NiOx} / \mathrm{NiOOx}$ species (particle size and morphology) and the stability of the oxide attached at the surface of the electrode. Further, it also discloses the complex reaction system involved during the catalyst activity in homogeneous phase and its progressive anchoring and water oxidation activity in solid supports. It thus brings light to this very thin border between the homogeneous and heterogeneous activity summarized in Scheme 1 and Figure 8. Moreover, it is striking to see the spectacular increase of stability of the molecular $\mathbf{2}^{\mathbf{2}-}$ complex, with Me-substituted ligand $\mathrm{L}^{2}$, as compared to $\mathrm{L}^{1}$ under exactly the same conditions and thus manifest how small variations on the organic ligands can strongly influence the combination of reactions involved in the catalyst behavior.

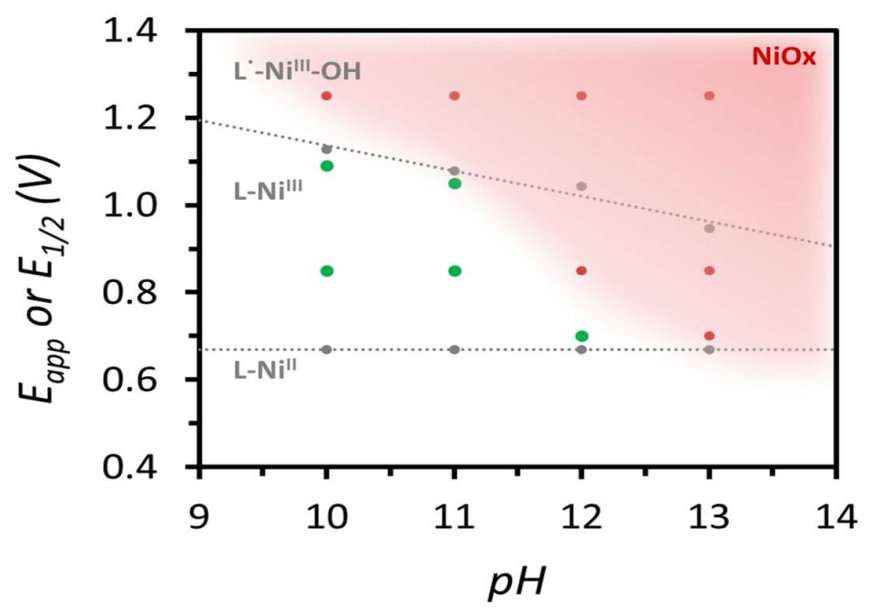

Figure 8. Pourbaix diagram of complex $\mathbf{1}^{\mathbf{2}-}$ with experimental redox potential as grey points. Points in green represent the CPE performed in those $\mathrm{pH}$ and $E_{\text {app }}$ conditions that did not form NiOx whereas points in red represent the $\mathrm{CPE}$ where $\mathrm{NiOx}$ was detected on the electrode. 
Overall the work described here indicates how thorough, cautious and careful analysis and interpretations should be done to fully understand the complicated behavior of Ni complexes as water oxidation catalysts.

\section{ASSOCIATED CONTENT}

Extended experimental methods, synthetic details, crystallographic procedure, electrochemical analyses, physical characterizations, computational details and Cartesian coordinates of all structures reported (PDF). The crystallographic data for the crystal structure of $\mathbf{2}^{\mathbf{2 -}}$ and $\mathbf{3}^{\mathbf{2}}$, with CCDC 1870803 and 1870804 respectively, are found in the CIF file.

\section{AUTHOR INFORMATION}

\section{Corresponding Author}

*E-mail: allobet@iciq.cat.

\section{Present Addresses}

${ }^{\perp}$ Present address: LCC-CNRS, Universite de Toulouse, CNRS, UPS, 205, route de Narbonne, F31077 Toulouse, France.

\section{Author Contributions}

The manuscript was written through contributions of all authors. All authors have given approval to the final version of the manuscript.

\section{Funding Sources}

Any funds used to support the research of the manuscript should be placed here (per journal style).

\section{Notes}

The authors declare no competing financial interest. 



\section{ACKNOWLEDGMENT}

MINECO and FEDER are gratefully acknowledged (CTQ2016-80058-R, CTQ2015-73028-EXP, SEV 2013-0319, ENE2016-82025-REDT (FOTOFUEL), CTQ2016-81923-REDC (INTECAT). P. G.-B. acknowledges "La Caixa" foundation for the $\mathrm{PhD}$ grant. 


\section{REFERENCES}

(1) McEvoy, J. P.; Brudvig, G. W. Water-splitting chemistry of photosystem II. Chem. Rev. 2006, $106,4455-4483$.

(2) Melis, A. Photosynthesis-to-fuels: from sunlight to hydrogen, isoprene, and botryococcene production. Energy Environ. Sci. 2012, 5 (2), 5531-5539.

(3) Berardi, S.; Drouet, S.; Francàs, L.; Gimbert-Suriñach, C.; Guttentag, M.; Richmond, C.; Stoll, T.; Llobet, A. Molecular artificial photosynthesis. Chem. Soc. Rev. 2014, 43 (22), 7501-7519.

(4) Nocera, D.G. Solar Fuels and Solar Chemicals Industry. Acc. Chem. Res. 2017, 50, 616-619.

(5) Kärkäs, M. D.; Åkermark, B. Water oxidation using earth-abundant transition metal catalysts: opportunities and challenges. Dalton Trans. 2016, 45 (37), 14421-14461.

(6) Wang, N.; Zheng, H.; Zhang, W.; Cao, R. Mononuclear first-row transition-metal complexes as molecular catalysts for water oxidation. Chin. J. Catal. 2018, 39, 228-244.

(7) Singh, A.; Spiccia, L. Water oxidation catalysts based on abundant 1st row transition metals. Coord. Chem. Rev. 2013, 257, 2607-2622.

(8) Garrido-Barros, P.; Gimbert-Suriñach, C.; Matheu, R.; Sala, X.; Llobet, A. How to make an efficient and robust molecular catalyst for water oxidation. Chem. Soc. Rev. 2017, 46, 6088-6098.

(9) Sheelan, S. W.; Thomsen, J. M.; Hintermair, U.; Crabtree, R. H.; Brudvig, G.W.; Schmuttenmaer, C. A. A molecular catalyst for water oxidation that binds to metal oxide surfaces. Nat. Commun. 2015, 6, 6469-6477.

(10) Francàs, L.; Sala, X.; Benet-Buchholz, J.; Escriche, L.; Llobet, A. A Ru-Hbpp-Based WaterOxidation Catalyst Anchored on Rutile TiO2*. ChemSusChem, 2009, 2, 321-329. 
(11) Sander, A. C.; Schober, A.; Dechert, S.; Meyer, F. A Pyrazolate-Bridged Bis(pentadentate) Ligand and Its Dinuclear Ruthenium Complex. Eur. J. Inorg. Chem. 2015, 4348-4353.

(12) Radaram, B.; Ivie, J. A.; Singh, W. M.; Grudzient, R. M.; Reibenspies, J. H.; Webster C. E.; Zhao, X. Water Oxidation by Mononuclear Ruthenium Complexes with TPA-Based Ligands. Inorg. Chem. 2011, 50, 10564-10571.

(13) Ellis, W. C.; McDaniel, N. D.; Bernhard, S.; Collins, T. J. Fast Water Oxidation Using Iron. J. Am. Chem. Soc. 2010, 132, 10990-10991.

(14) Wang, J.-W.; Sahoo, P.; Lu, T.-B. Reinvestigation of Water Oxidation Catalyzed by a Dinuclear Cobalt Polypyridine Complex: Identification of CoOx as a Real Heterogeneous Catalyst. ACS Catal. 2016, $6,5062-5068$

(15) Hong, D.; Mandal, S.; Yamada, Y.; Lee, Y.-M.; Nam, W.; Llobet, A.; Fukuzumi, S. Water Oxidation Catalysis with Nonheme Iron Complexes under Acidic and Basic Conditions: Homogeneous or Heterogeneous? Inorg. Chem. 2013, 52, 9522-9531.

(16) Daniel, Q.; Ambre, R. B.; Zhang, B.; Philippe, B.; Chen, H.; Li, F.; Fan, K.; Ahmadi, S.; Rensmo, H.; Sun, L. Re-Investigation of Cobalt Porphyrin for Electrochemical Water Oxidation on FTO Surface: Formation of CoOx as Active Species. ACS Catal. 2017, 7, 1143-1149.

(17) Najafpour, M. M.; Feizi, H. Water oxidation catalyzed by two cobalt complexes: new challenges and questions. Catal. Sci. Technol. 2018, 8, 1840-1848.

(18) Singh, A.; Chang, S. L. Y.; Hocking, R. K.; Bach, U.; Spiccia, L. Highly active nickel oxide water oxidation catalysts deposited from molecular complexes. Energy Environ. Sci. 2013, 6, 579586. 
(19) Singh, A.; Chang, S. L. Y.; Hocking, R. K.; Bach, U.; Spiccia, L. Anodic deposition of NiOx water oxidation catalysts from macrocyclic nickel(II) complexes. Catal. Sci. Technol. 2013, 3, 17251732.

(20) Wang, D.; Ghiirlanda, G.; Allen, J. P. Water Oxidation by a Nickel-Glycine Catalyst. J. Am. Chem. Soc. 2014, 136, 10198-10201.

(21) Najafpour, M. M.; Feizi, H. Water oxidation by Ni(1,4,8,11-tetraazacyclotetradecane)* in the presence of carbonate: new findings and an alternative mechanism. Dalton Trans. 2018, 47, 65196527

(22) Han, Y.; Wu, Y.; Lai, W.; Cao, R. Electrocatalytic Water Oxidation by a Water-Soluble Nickel Porphyrin Complex at Neutral pH with Low Overpotential. Inorg. Chem. 2015, 54, 5604-5613.

(23) Lin, J.; Kang, P.; Liang, X.; Ma, B.; Ding, Y. Homogeneous electrocatalytic water oxidation catalyzed by a mononuclear nickel complex. Electrochimica Acta, 2017, 258, 353-359.

(24) Wang, D.; Bruner, C. O. Catalytic Water Oxidation by a Bio-inspired Nickel Complex with a Redox-Active Ligand. Inorg. Chem. 2017, 56, 13638-13641.

(25) Garrido-Barros, P.; Funes-Ardoiz, I.; Drouet, S.; Benet-Buchholz, J.; Maseras, F.; Llobet, A. Redox Non-innocent Ligand Controls Water Oxidation Overpotential in a New Family of Mononuclear Cu-Based Efficient Catalysts. J. Am. Chem. Soc. 2015, 137, 6758-6761.

(26) Ottenwaelder, X.; Aukauloo, A.; Journaux, Y.; Carrasco, R.; Cano, J.; Cervera, B.; Castro, I.; Curreli, S.; Muñoz, M. C.; Roselló, A. L.; Soto, B.; Ruiz-García, R. Synthesis, structure, spectroscopy and redox chemistry of square-planar nickel(II) complexes with tetradentate ophenylenedioxamidates and related ligands. Dalton Trans. 2005, 0, 2516-2526. 
(27) Costentin, C.; Drouet, S.; Robert, M.; Savéant, J.-M. Turnover Numbers, Turnover Frequencies, and Overpotential in Molecular Catalysis of Electrochemical Reactions. Cyclic Voltammetry and Preparative-Scale Electrolysis. J. Am. Chem. Soc. 2012, 134, 11235.

(28) Ottenwaelder, X.; Ruiz-García, R.; Blodin, G.; Carrasco, R.; Cano, J.; Lexa, D.; Journaux, Y.; Aukauloo, A. From metal to ligand electroactivity in nickel(II) oxamato complexes. Chem. Commun., 2004, 0, 504-505.

(29) Wang, J.-W.; Hou, C.; Huang, H.-H.; Liu, W.-J.; Ke, Z.-F.; Lu, T.-B. Further insight into the electrocatalytic water oxidation by macrocyclic nickel(II) complexes: the influence of steric effect on catalytic activity. Catal. Sci. Technol. 2017, 7, 5585-5593.

(30) Luo, G.-Y.; Huang, H.-H.; Wang, J.-W.; Lu, T.-B. Further Investigation of a Nickel-Based Homogeneous Water Oxidation Catalyst with Two cis Labile Sites. ChemSusChem 2016, 9, 485-491.

(31) Zhang, M.; Zhang, M.-T.; Hou, C.; Ke, Z.-F.; Lu, T.-B. Homogeneous electrocatalytic water oxidation at neutral $\mathrm{pH}$ by a robust macrocyclic nickel(II) complex. Angew. Chem. Int. Ed. 2014, 53, 13042-13048.

(32) Wang, L.; Duan, L.; Ambre, R. B.; Daniel, Q.; Chen, H.; Sun, J.; Das, B.; Thapper, A.; Uhlig, J.; Dinér, P.; Sun, L. A nickel (II) PY5 complex as an electrocatalyst for water oxidation. J. Catal. 2016, 335, 72-78.

(33) Garrido-Barros, P.; Gimbert-Suriñach, C.; Moonshiram, D.; Picón, A.; Monge, P.; Batista, V. S.; Llobet, A. Electronic $\pi$-Delocalization Boosts Catalytic Water Oxidation by $\mathrm{Cu}(\mathrm{II})$ Molecular Catalysts Heterogenized on Graphene Sheets. J. Am. Chem. Soc. 2017, 139, 12907-12910.

(34) Trotochaud, L.; Young, S. L.; Ranney, J. K.; Boettcher, S. W. Nickel-Iron Oxyhydroxide Oxygen-Evolution Electrocatalysts: The Role of Intentional and Incidental Iron Incorporation. J. Am. Chem. Soc. 2014, 136, 6744-6753. 
(35) Stevens, M. B.; Trang, C. D. M.; Enman, L. J.; Deng, J.; Boettcher, S. W. Reactive Fe-Sites in Ni/Fe (Oxy)hydroxide Are Responsible for Exceptional Oxygen Electrocatalysis Activity. J. Am. Chem. Soc. 2017, 139, 11361-11364.

(36) Dionigi, F.; Strassser, P. NiFe-Based (Oxy)hydroxide Catalysts for Oxygen Evolution Reaction in Non-Acidic Electrolytes. Adv. Energy Mater. 2016, 6, 1600621.

(37) Stevens, M. B.; Enman, L. J.; Batchellor, A. S.; Cosby, M. R.; Vise, A. E.; Trang, C. D. M.; Boettcher, S. W. Measurement Techniques for the Study of Thin Film Heterogeneous Water Oxidation Electrocatalysts. Chem. Mater. 2017, 29, 120-140.

(38) McCrory, C. C. L.; Jung, S.; Peters, J. C.; Jaramillo, T. F. Benchmarking Heterogeneous Electrocatalysts for the Oxygen Evolution Reaction. J. Am. Chem. Soc. 2013, 135, 16977-16987.

(39) Chakthranont, P.; Kibsgaard, J.; Gallo, A.; Park, J.; Mitani, M.; Sokaras, D.; Kroll, T.; Sinclair, R.; Mogensen, M. B.; Jaramillo, T. F. Effects of Gold Substrates on the Intrinsic and Extrinsic Activity of High-Loading Nickel-Based Oxyhydroxide Oxygen Evolution Catalysts. ACS Catal. 2017, 7 , 5399-5409.

(40) Guo, D.; Qi, J.; Zhang, Q.; Cao, R. Surface Electrochemical Modification of a Nickel Substrate to Prepare a NiFe-based Electrode for Water Oxidation. ChemSusChem 2017, 10, 394-400.

(41) Görlin, M.; De Araújo, J. F.; Schmies, H.; Bernsmeier, D.; Dresp, S.; Gliech, M.; Jusys, Z.; Chernev, P.; Kraehnert, R.; Dau, H.; Strasser, P. Tracking Catalyst Redox States and Reaction Dynamics in Ni-Fe Oxyhydroxide Oxygen Evolution Reaction Electrocatalysts: The Role of Catalyst Support and Electrolyte pH. J. Am. Chem. Soc. 2017, 139, 2070-2082.

(42) Qi, J.; Zhang, W.; Xiang, R.; Liu, K.; Wang, H.-Y.; Chen, M.; Han, Y.; Cao, R. Porous NickelIron Oxide as a Highly Efficient Electrocatalyst for Oxygen Evolution Reaction. Adv. Sci. 2015, 2, 1500199. 


\section{Insert Table of Contents Graphic and Synopsis Here}

Water oxidation catalysis with Ni complexes: Molecular or oxide? This manuscript explores the conditions under which a family of Ni complexes behave as active molecular water oxidation catalysts and those under which they lead to the formation of oxides, which end up being the active water oxidation catalysts.

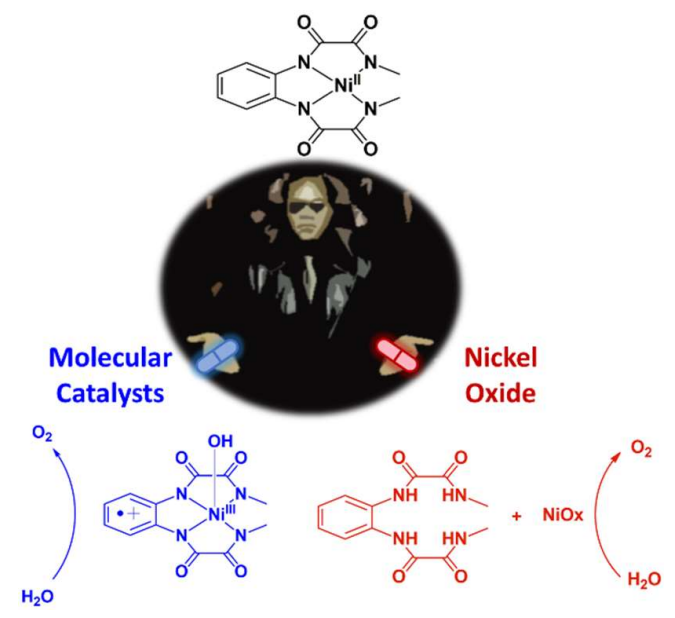

